\title{
A Review of Treatment for Herpes Zoster Keratitis
}

\author{
Taariq K Mohammed, ${ }^{1}$ Elisabeth J Cohen² and Bennie H Jeng ${ }^{1}$ \\ 1. Department of Ophthalmology and Visual Sciences, University of Maryland School of Medicine, Baltimore, MD, USA; 2. Department of \\ Ophthalmology, NYU Grossman School of Medicine, New York, NY, USA
}

\section{Keywords}

Herpes zoster, herpes zoster ophthalmicus, herpes zoster keratitis, vaccination, Zoster Eye Disease Study

Disclosures: Taariq K Mohammed, Elisabeth $\mathrm{J}$ Cohen and Bennie $\mathrm{H}$ Jeng have no financial or non-financial relationships or activities to declare in relation to this article.

Review process: Double-blind peer review.

Compliance with ethics: This study involves a review of the literature and did not involve any studies with human or animal subjects performed by any of the authors.

Data availability: Data sharing is not applicable

to this article as no datasets were generated or analysed during the writing of this article.

Authorship: The named authors meet the Internationa Committee of Medical Journal Editors (ICMJE) criteria for authorship of this manuscript, take responsibility for the integrity of the work as a whole, and have given final approval for the version to be published.

Access: This article is freely accessible

at touchOPHTHALMOLOGY.COM.

(C) Touch Medical Media 2021

Received: 23 September 2021

Accepted: 30 November 2021

Published online: 20 December 2021

Citation: touchREVIEWS in

Ophthalmology. 2021;15(2):43-5

Corresponding author: Bennie $\mathrm{H}$ Jeng,

Department of Ophthalmology and Visual sciences,

University of Maryland School of Medicine, 419

W. Redwood Street, Suite 470, Baltimore, MD

21201, USA. E: bjeng@som.umaryland.edu

Support: Supported by NEI/NIH cooperative agreement U10 EY 026869
Varicella zoster virus is a double-stranded DNA herpesvirus that resides dormant in the sensory nerve ganglia after primary infection of varicella/chicken pox. While primary infection can be mild, on reactivation, the virus typically causes a painful vesicular rash called herpes zoster ( $\mathrm{HZ}$ ), that affects approximately 1 million people per year in the USA. ${ }^{1}$ The incidence of HZ has quadrupled in the past 60 years and continues to increase worldwide. ${ }^{2}$ Although it is generally more common with age, the incidence in younger patients is rising more quickly, and the average age of initial presentation of $\mathrm{HZ}$ is decreasing, with reports citing an average age of 56-59 years. ${ }^{3-5} \mathrm{It}$ has been argued that this change may be related to the increase in childhood varicella vaccinations, but the incidence of $\mathrm{HZ}$ has been increasing in countries where widespread vaccination is not given and has also been stable in patients over age 65 , so other factors are likely involved. ${ }^{4-7}$ The sequelae of $\mathrm{HZ}$ outside of ocular disease include chronic pain secondary to post-herpetic neuralgia (PHN), and potentially lethal systemic complications, including stroke. ${ }^{8,9}$ Around $10-20 \%$ of $\mathrm{HZ}$ involves the ophthalmic branch of the trigeminal nerve and is called herpes zoster ophthalmicus (HZO). ${ }^{10-12}$

\section{General presentation and management of herpes zoster ophthalmicus}

$\mathrm{HZ}$ typically results in a painful, unilateral, dermatomal vesicular rash. Ocular involvement in $\mathrm{HZO}$ is common, especially when the Hutchinson sign (lesions on the nose) is observed: in one case series of 259 patients with $\mathrm{HZO}, 66.0 \%$ had ocular involvement. ${ }^{13}$ The most frequent ocular manifestations of $\mathrm{HZO}$ in those patients were conjunctivitis (56.8\%) and anterior uveitis (17.8\%). Keratitis is also a common presentation, with an incidence that varies by subtype, including stromal (6.6\%), epithelial (5.0\%) and endothelial (1.2\%). ${ }^{13}$ Anterior uveitis can be an infectious manifestation in both early and late forms. ${ }^{14} \mathrm{HZO}$ can also result in scleritis, trabeculitis, optic neuritis, retinal vasculitis, giant cell arteritis, retinopathy and cranial nerve defects..$^{10,15}$ After acute presentation, HZO can progress into chronic or recurrent disease. Chronic HZO occurs in $23.0 \%$ of patients, and recurrence rates increase with time from $8.0 \%$ of patients at 1 year to $25.0 \%$ of patients at 5 years after the original acute $\mathrm{HZO}$ onset. ${ }^{16}$ The early manifestations of herpes zoster keratitis $(\mathrm{HZK})$ are related to the active virus, and present as dendriform epithelial keratitis. Later forms of HZK are more related to an inflammatory immune response, and can cause stromal keratitis or endotheliitis. After appropriate management of acute or recurrent corneal disease, long-term damage from HZK can result in neurotrophic keratitis (NK) and corneal scarring., ${ }^{3.8}$

The management of $\mathrm{HZ}$ involves prevention with vaccination. Vaccination is recommended by the Centers for Disease Control and Prevention (CDC) for all immunocompetent patients over the age of 50 years. There are two vaccines available worldwide: a single-dose zoster vaccine live (ZVL) that is $51 \%$ effective (Zostavax ${ }^{\oplus}$; Merck \& Co. Inc., West Point, PA, USA) and a two-dose recombinant zoster vaccine (RZV) that is $96.0 \%$ effective (Shingrix ${ }^{\circledR}$; GlaxoSmithKline, Rixensart, Belgium). ${ }^{17.18}$ In addition to being more effective than the ZVL, the RZV has fewer contraindications, although it does require two doses and causes more acute side effects. The most common side effects of vaccination are local injection-site reactions or mild systemic reactions, but rare ophthalmologic reactivation of $\mathrm{HZ}$ has been reported, sometimes with severe consequences, including corneal perforation. ${ }^{10,19,20}$ The RZV is approved by the US Food and Drugs Administration for adults aged 
Figure 1: Chronic stromal keratitis from herpes zoster ophthalmicus

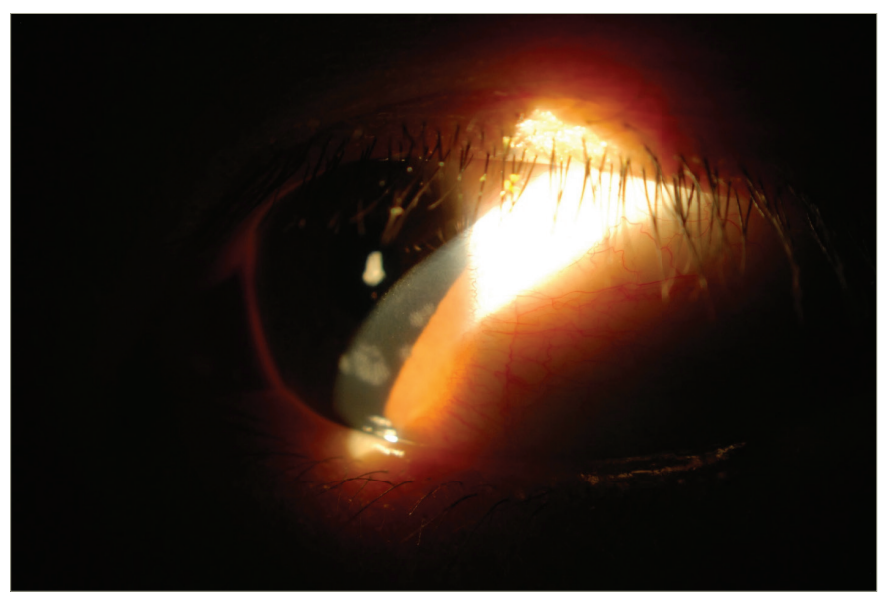

50 years and older, and is preferred over the $\mathrm{ZVL}$, which is no longer available in the USA since 2020. The RZV is recommended by the CDC for persons with a history of zoster or past vaccination with ZVL. ${ }^{21}$

Oral antiviral treatment options for $\mathrm{HZ}$ include $1 \mathrm{~g}$ valacyclovir three times daily, $800 \mathrm{mg}$ acyclovir five times daily or $500 \mathrm{mg}$ famciclovir three times daily, with initiation of therapy within 72 hours of symptom onset for a duration of 7-10 days. ${ }^{22-24}$

\section{Early and late manifestations of herpes zoster keratitis}

Early HZK can present as dendriform epithelial keratitis, and is related to active virus and should consequently be treated with antiviral medications. ${ }^{3,8}$ Treatment is often with the same oral antiviral medications as for $\mathrm{HZ}$, typically acyclovir or valacyclovir, but in refractory cases topical ganciclovir $0.15 \%$ gel five times daily has been reported to aid management. ${ }^{25}$ Epithelial disease can occur later as mucous plaque keratitis or delayed pseudodendrites and, in addition to oral antivirals for these patients, the mucous plaques can be debrided and topical acetylcysteine $10.0 \%$ drops can be added. ${ }^{8,26}$

The treatment of inflammatory complications of HZK, such as stromal or endothelial keratitis, centres on topical steroids. The most commonly used regimen is prednisolone acetate $1 \%$ four times daily, but surveys of current treatment among cornea providers show that a range of topical low- and high-potency steroids are used at different dosing frequencies ranging from daily to greater than five times daily. ${ }^{27}$ Stromal or nummular keratitis (Figure 1) can lead to complications such as corneal scarring, neovascularization, ulceration or lipid keratopathy that may require surgical interventions. ${ }^{3,8}$ Endotheliitis, or disciform keratitis, likewise responds well to topical steroids but, if significant endothelial cell loss occurs, surgical intervention such as endothelial keratoplasty (EK) or penetrating keratoplasty (PK) may need to be considered, depending on the degree of stromal damage. ${ }^{26}$ PK does carry the risk of increased complications over EK, including secondary glaucoma and ocular surface problems due to NK that may benefit from tarsorrhaphy. ${ }^{28}$ Iritis can occur as part of early or late HZO. ${ }^{3,8}$

\section{Complications from herpes zoster keratitis}

NK is a complication that can also develop from damage to the corneal nerves from $\mathrm{HZO}$ (Figure 2), and this can lead to secondary complications,
Figure 2: Subepithelial haze from neurotrophic keratitis secondary to herpes zoster ophthalmicus

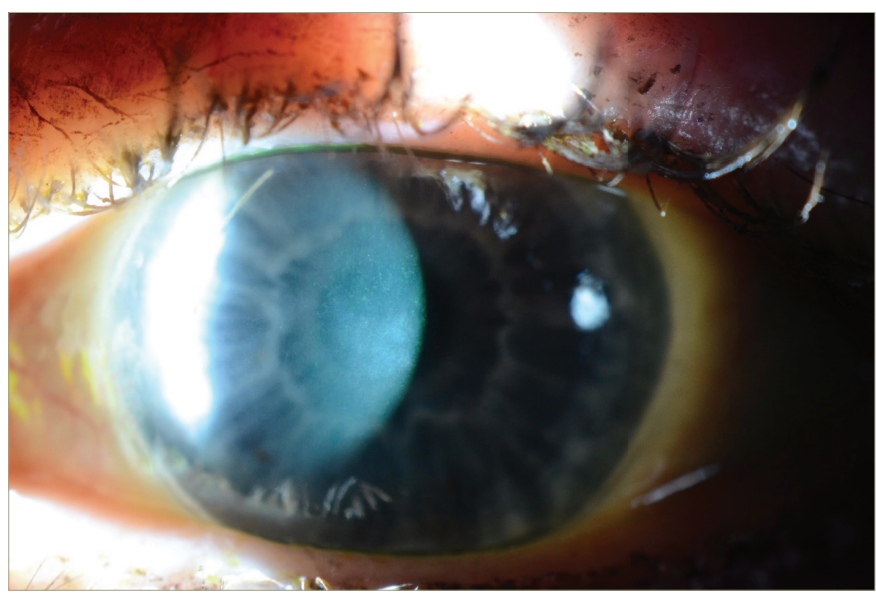

Figure 3: Persistent epithelial defect with early stromal melting in an eye with neurotrophic keratitis secondary to herpes zoster ophthalmicus

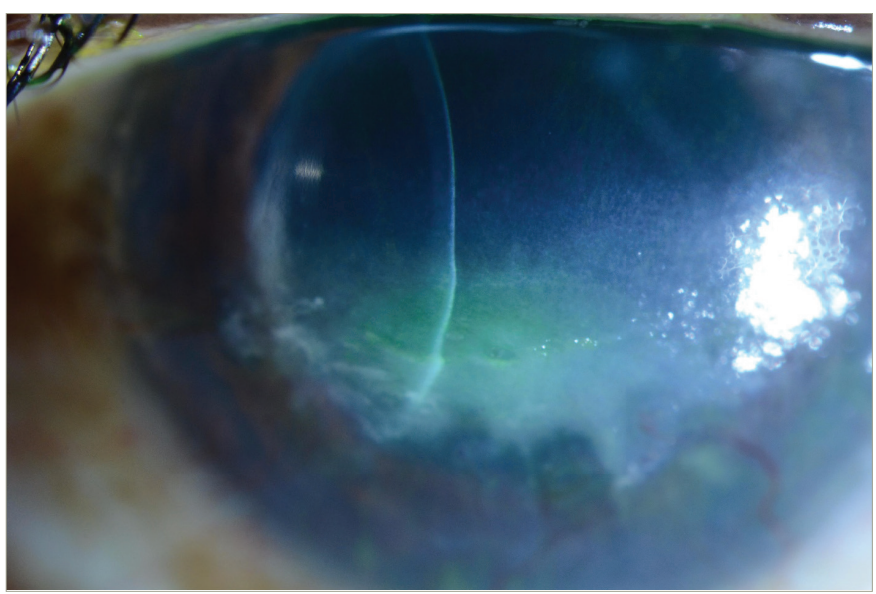

such as persistent epithelial defects (Figure 3), microbial superinfection and perforation. ${ }^{8.29} \mathrm{NK}$ is more common in older patients, and it can be managed with lubrication, punctal plugs, tarsorrhaphy or scleral lenses. ${ }^{24}$ Recombinant human nerve growth factor and corneal neurotization are newer modalities to treat and address NK. ${ }^{29}$ Corneal perforations, if smaller than $1.5 \mathrm{~mm}$, can be managed with cyanoacrylate or fibrin glue and ocular antihypertensives. Amniotic membrane or conjunctival grafts and flaps can also help but, in severe cases, a PK may be required. ${ }^{29}$

Secondary corneal scarring and astigmatism can be managed with contact lenses and surgical options, including phototherapeutic keratectomy (PTK) and PK. ${ }^{30}$ Rigid gas permeable lenses can be used if there is normal or mildly decreased corneal sensation but, in cases of more severe neurotrophic keratopathy, scleral contact lenses are a better option. ${ }^{8}$ Corneal surgical procedures carry the risk of persistent epithelial defects and subsequent stromal melting, as surgery can worsen the pre-existing neurotrophic state, and outcomes are best when active inflammation, intraocular pressure and NK are optimized pre-operatively with artificial tears, punctal plugs, cyclosporine and topical or oral antivirals. ${ }^{26}$ For stromal scarring, PTK with mitomycin $0.02 \%$, or deep anterior lamellar keratoplasty can be considered. For severe endothelial dysfunction, EK should be considered, and for 
combined stromal scarring and endothelial dysfunction, PK can be considered. In either scenario, any active disease should be quiescent for 3 months prior to surgery, and serious consideration should be given to starting treatment dosing of oral antivirals several weeks prior to surgery, continuing through the initial post-operative period. Subsequently, oral antiviral prophylaxis should be maintained. ${ }^{8}$ Keratoprostheses have also been used, but these eyes tend to have a worse outcome than in cases with herpes simplex virus (HSV). ${ }^{31}$ Conjunctival grafts or flaps can be used for peripheral ulcers or persistent epithelial defects from NK, and exposure can be managed surgically with tarsorrhaphy or eyelid weights. ${ }^{8}$

\section{Chronic and recurrent herpes zoster keratitis}

Management of chronic or recurrent disease can be challenging, and topical corticosteroids have been the mainstay of treatment. However, the concept of recurrence or chronicity of HZK prompts discussion of prophylaxis, as there is evidence that, during clinically quiescent times, subclinical viral transcription and translation may occur when an intact cell-mediated response is disrupted. ${ }^{32-34}$ Unfortunately, there is no consensus on exact dosing, frequency, duration or even effectiveness of treatment. Long-term prophylaxis with oral antivirals is commonly used by cornea specialists, with different dosing including $1 \mathrm{~g}$ valacyclovir daily or $800 \mathrm{mg}$ acyclovir twice daily. ${ }^{8}$ In a survey from $2012,{ }^{27} 56 \%$ of corneal specialists reported that they believed oral antiviral prophylaxis was effective, and that number increased to $71 \%$ in a 2019 survey. ${ }^{22}$ In a retrospective study by Miserocchi and colleagues, $35 \%$ of eyes affected by $\mathrm{HZO}$ and $39 \%$ of eyes affected by HSV had fewer episodes of inflammation with use of low-dose antiviral prophylaxis. ${ }^{35}$ As this decrease in HSV recurrence was similar to that found in the Herpetic Eye Disease Study, ${ }^{36}$ it is possible that low-dose, suppressive antiviral therapy could also work for $\mathrm{HZ}$. However, there are no further data to support whether oral antiviral prophylaxis is effective in reducing the anterior segment complications associated with $\mathrm{HZO}$.

The ongoing Zoster Eye Disease Study (ZEDS) (Clinicaltrials.gov: NCT03134196) ${ }^{37}$ is a prospective, multicentre, randomized controlled trial that seeks to determine if prolonged suppressive antiviral therapy (1 g valacyclovir daily) reduces anterior segment complications of HZO. Specifically, the primary endpoint is delay in time to first occurrence by 12 months of new or worsening dendriform epithelial keratitis, stromal keratitis (with and without ulceration), endotheliitis and iritis. Secondary endpoints include evaluating the treatment effect on primary endpoints 6 months after discontinuation of therapy to determine if there is a longterm effect. The impact of this therapy on PHN will also be assessed. The results of ZEDS will help establish standard of care for the role of prophylactic therapy to prevent $\mathrm{HZO}$ complications of the anterior segment. Participation in ZEDS is encouraged. ${ }^{38}$

\section{Conclusion}

$\mathrm{HZ}$ is a complex disease that can have multiple ocular manifestations that vary in severity. The treatment of HZK centres on oral and/or topical antivirals for active epithelial disease and topical steroids for immunemediated stromal and endothelial disease..$^{22-24,27} \mathrm{HZK}$ is often recurrent or chronic, sometimes complicated by NK, and can ultimately lead to stromal scarring or endothelial dysfunction, possibly requiring surgery. ${ }^{8}$ Vaccination is an effective method of decreasing the incidence of $\mathrm{HZO}^{21}$ Other ophthalmic manifestations, such as glaucoma, and systemic issues, such as PHN, should be co-managed with appropriate specialists. ${ }^{8}$ Management of chronic and recurrent HZK disease is challenging, and currently there is little evidence to guide treatment with antiviral medications. The results of the ongoing ZEDS trial will help establish the standard of care. ${ }^{3} \square$
1. Suaya JA, Chen SY, Li Q, et al. Incidence of herpes zoster and persistent post-zoster pain in adults with or without diabetes in the United States. Open Forum Infect Dis. 2014;1:ofu049.

2. Kawai K, Yawn BP, Wollan P, Harpaz R. Increasing incidence of herpes zoster over a 60-year period from a population-based study. Clin Infect Dis. 2016;63:221-6.

3. Cohen EJ. Management and prevention of herpes zoster ocular disease. Cornea. 2015;34(Suppl. 10):S3-8.

4. Chan AY, Conrady CD, Ding K, et al. Factors associated with age of onset of herpes zoster ophthalmicus. Cornea. 2015;34:535-40.

5. Davies EC, Pavan-Langston D, Chodosh J. Herpes zoster ophthalmicus: declining age at presentation. Br J Ophthalmol. 2016;100:312-4.

6. Harpaz R, van Hoek AJ. Point-counterpoint: the Hope-Simpson hypothesis and its implications regarding an effect of routine varicella vaccination on herpes zoster incidence. I Infect Dis. varicella vaccination on herp

7. Wolfson $\amalg$, Daniels VJ, Altland A, et al. The impact of varicella vaccination on the incidence of varicella and herpes zoster in the United States: updated evidence from observation databases, 1991-2016. Clin Infect Dis. 2020;70:995-1002.

8. Vadoothker S, Jeng BH. Management of chronic complications associated with herpes zoster ophthalmicus. Curr Opin Ophthalmol. 2018;29:334-9

9. Patterson BJ, Rausch DA, Irwin DE, et al. Analysis of vascular event risk after herpes zoster from 2007 to 2014 US insurance claims data. Mayo Clin Proc. 2019;94:763-75.

10. Liesegang TJ. Herpes zoster ophthalmicus natural history, risk factors, clinical presentation, and morbidity. Ophthalmology. 2008:115(Suppl. 2):S3-12.

11. Kong $\mathrm{CL}$, Thompson RR, Porco $\mathrm{TC}$, et al. Incidence rate of herpes zoster ophthalmicus: a retrospective cohort study from 1994 through 2018. Ophthalmology. 2020;127:324-30.

12. Thompson RR, Kong CL, Porco TC, et al. Herpes zoster and post-herpetic neuralgia: changing incidence rates from 1994 to 2018 in the United States. Clin Infect Dis. 2021;73:e3210-7.

13. Szeto SK, Chan TC, Wong RL, et al. Prevalence of ocular manifestations and visual outcomes in patients with herpes zoster ophthalmicus. Cornea. 2017;36:338-42.
14. Kido $S$, Sugita $S$, Horie $S$, et al. Association of varicella zoster virus load in the aqueous humor with clinical manifestations of anterior uveitis in herpes zoster ophthalmicus and zoster sine anterior uveitis in herpes zoster ophthalm

15. Gilden D, White T, Khmeleva N, et al. Prevalence and distribution of VZV in temporal arteries of patients with giant cell arteritis. Neurology. 2015;84:1948-55

16. Tran KD, Falcone MM, Choi DS, et al. Epidemiology of herpes zoster ophthalmicus: recurrence and chronicity. Ophthalmology. 2016;123:1469-75.

17. Gibbons A, Galor A. Current vaccines for the prevention of herpes zoster. Curr Opin Ophthalmol. 2018;29:355-9.

18. Boutry C, Hastie A, Diez-Domingo J, et al. The adjuvanted recombinant zoster vaccine confers long-term protection against herpes zoster: interim results of an extension stud against herpes zoster: Interim results of an extension study Infect Dis. 2021:ciab629.

19. Lehmann A, Matoba A. Reactivation of herpes zoster stromal keratitis after $\mathrm{HZ} / \mathrm{su}$ adjuvanted herpes zoster subunit vaccine. keratitis after HZ/su adjuvanted
Ophthalmology. 2018;125:1682.

20. Jabbour S, Shekhawat NS, Chen A, Woreta FA. Presumed Herpes zoster ophthalmicus reactivation following recombinant zoster vaccination. Cornea. 2021;40:248-50.

21. Dooling KL, Guo A, Patel M, et al. Recommendations of the Advisory committee on immunization practices for use of herpes zoster vaccines. MMWR Morb Mortal Wkly Rep. 2018;67:103-8.

22. Lo DM, Jeng BH, Gillespie $C$, et al. Current practice patterns and opinions on the management of recent-onset or chronic herpes zoster ophthalmicus of Zoster Eye Disease Study investigators. Cornea. 2019;38:13-7.

23. Colin J, Prisant O, Cochener B, et al. Comparison of the efficacy and safety of valaciclovir and acyclovir for the treatment of herpes zoster ophthalmicus. Ophthalmology. 2000;107:1507-11.

herpes zoster ophthalmicus. Ophthalmology. 2000;
24. Ghaznawi N, Virdi A, Dayan A, et al. Herpes zoster

ophthalmicus: comparison of disease in patients 60 years and older versus younger than 60 years. Ophthalmology. 2011;118:2242-50.

25. Aggarwal S, Cavalcanti BM, Pavan-Langston D. Treatment of pseudodendrites in herpes zoster ophthalmicus with topica ganciclovir 0.15\% gel. Cornea. 2014:33:109-13.

26. Kaufman SC. Anterior segment complications of herpes zoster ophthalmicus. Ophthalmology. 2008:115(Suppl. 2):S24-32.

27. Sy A, McLeod SD, Cohen EJ, et al. Practice patterns and opinions in the management of recurrent or chronic herpes zoster ophthalmicus. Cornea. 2012;31:786-90.

28. Tanaka TS, Hood CT, Kriegel MF, et al. Long-term outcomes of penetrating keratoplasty for corneal complications of herpes zoster ophthalmicus. Br J Ophthalmol. 2019;103:1710-5.

29. Cohen $\mathrm{EJ}$, Jeng BH. Herpes zoster: a brief definitive review. Cornea. 2021;40:943-9.

30. Hassan OM, Farooq AV, Soin K, et al. Management of corneal scarring secondary to herpes zoster keratitis. Cornea. 2017;36:1018-23.

31. Brown $\mathrm{CR}$, Wagoner MD, Welder JD, et al. Boston keratoprosthesis type 1 for herpes simplex and herpes zoster keratopathy. Cornea. 2014;33:801-5.

32. Cohrs RJ, Mehta SK, Schmid DS, et al. Asymptomatic reactivation and shed of infectious varicella zoster virus in astronauts. J Med Virol. 2008;80:1116-22.

33. Devlin ME, Gilden DH, Mahalingam R, et al. Peripheral blood mononuclear cells of the elderly contain varicella-zoster virus DNA. I Infect Dis. 1992;165:619-22.

34. Wilson A, Sharp M, Koropchak CM, et al. Subclinical varicellazoster virus viremia, herpes zoster, and T lymphocyte immunity to varicella-zoster viral antigens after bone marrow transplantation. J Infect Dis. 1992;165:119-26.

35. Miserocchi E, Fogliato G, Bianchi I, et al. Clinical features of ocular herpetic infection in an italian referral center. Cornea. 2014;33:565-70

36. Herpetic Eye Disease Study Group. Oral acyclovir for herpes simplex virus eye disease: effect on prevention of epithelial keratitis and stromal keratitis. Arch Ophthalmol. 2000;118:1030-6.

37. ClinicalTrials.gov. Zoster Eye Disease Study (ZEDS). ClinicalTrials. gov Identifier: NCT03134196. https://clinicaltrials.gov/ct2/show/ NCT03134196 (accessed 9 December 2021)

38. NYU Langone Health. Zoster Eye Disease Study. https://med. nyu.edu/research/zoster-eye-disease-study/ (accessed 9 December 2021). 